\title{
Max Weber entre liberalismo y republicanismo
}

\author{
José LuIS VILlacAÑAs BeRLANGA \\ Universidad de Murcia
}

\begin{abstract}
RESUMEN. Este artículo pretende analizar las diferencias entre democracia social y democracia política como procesos modernos, tal y como fueron comprendidos por Max Weber. Lo arquetípico de la modernidad reside, desde este punto de vista, en una convergencia de ambos procesos, tal y como se dio en países como USA y Gran Bretaña. El diagnóstico de Weber es que, mientras la democracia social puede organizarse sobre argumentos liberales, la democracia política no puede avanzar sin conceptos republicanos como el de virtud, rigor, responsabilidad y representación. Para Weber, estos valores sólo podrían hacerse presentes en Alemania a partir de una recepción adecuada y democrática de Nietzsche y en cierto modo esta recepción daría sentido a su obra.
\end{abstract}

Palabras clave: democracia, modernidad, liberalismo, responsabilidad política, representación política, F. Nietzsche, M. Weber.

\begin{abstract}
This article attempts to analyze the differences between social democracy and political democracy as modern processes, as these were understood by Max Weber. The archetype of modernity resides, from this point of view, in a convergence of both processes, as occurred in countries like the USA and Great Britain. Weber's diagnosis is that, whereas social democracy can be organizad around liberal arguments, political democracy cannot advance without republican concepts like those of virtue, rigour, responsibility and representation. For Weber, these values could only become present in Germany thanks to an adequate and democratic reception of Nietzsche, and in some way this reception could make sense of the former's work.
\end{abstract}

Keywords: democracy, modernity, liberalism, political responsability, political representación, F. Nietzsche, $M$. Weber.

1. Una obra en proceso. Debemos aprender todavía a leer la obra de Max Weber. Quiero decir, sobre todo, que debemos decidir el sentido y el valor de Economía y sociedad ${ }^{1}$, una obra redactada contra el poder inminente de la muerte, en la que Weber fue depositando todos sus saberes y experiencias. Pero sobre todo, esa obra fue escrita en el tiempo en que las ilusiones nacio-

1 Para este asunto se debe ver la introducción de Horst Baier, M. Rainer Lepsius, W. J. Mommsen y W. Schluchter a Wirtschaft und Gesellschaft, Die Stadt, MWG, I, 22-25, pp. VIIXVII, Tubingen, Mohr Siebeck, 1999, traducido también al inglés en Max Weber Studies, núm. 1, 2000, pp. 104-114. 
nalistas e imperialistas alemanas habían sucumbido, de facto, con el estancamiento primero, y luego derrota, de la Primera Guerra Mundial ${ }^{2}$. Por eso, para la inteligencia del lector de esta magna obra, el reto consiste sobre todo en identificar las líneas evolutivas de su pensamiento, las aperturas a la realidad, las reflexiones sobre los nuevos elementos sociales que se abrían en el horizonte y situarlas en las estructuras más constantes de su pensamiento, acreditadas desde antiguo, desde aquellas primeras intervenciones que deslumbraron al mundo académico alemán en su Antritsrede de $1895^{3}$.

Una de las esferas de acción ${ }^{4}$ en la que Weber sintió la necesidad de ajustar sus propios planteamientos a la nueva realidad de las cosas, tras las experiencias de 1914, fue sin duda la política. Y uno de los temas en los que concentró su atención, como consecuencia de los nuevos escenarios abiertos por la guerra, fue el de la democracia en la época de las masas. Tanto es así que Stefan Breuer ha podido sugerir que el tema central del último Weber sería el de la configuración de una cuarta forma de legitimidad, la democrática ${ }^{5}$. En cierto modo, he seguido estos planteamientos en algunos trabajos anteriores ${ }^{6}$. La política, sin embargo, siempre había sido un tema central de la reflexión weberiana, tanto desde la Eintrit-Vorlesung de $1895^{7}$, como desde sus estudios sobre la decadencia del mundo romano ${ }^{8}$. Su argumento se enriqueció a partir de su diagnóstico acerca de la evolución moderna y su resolución en la sociedad de masas. Finalmente, ante el callejón sin salida de la guerra, en la serie de artículos políticos que publicó en el Frankfurter All-

2 W. J. Mommsen, L'età dell' imperialismo. Milán, Feltrinelli, 1989. Como es natural, siempre hay que referirse a su magna obra Max Weber und die deutsche Politik, 1890-1920, Tübingen, Mohr, 1959. Recientemente, antes de morir, el autor se manifestó autocrítico con esta obra, por su especial énfasis en la línea de continuidad entre las ideas de Weber y las posteriores ideas de los nazis. El autor dejó de creer en un sencilla continuidad y reconoció que quizá su vieja creencia estaba determinada por factores familiares no especialmente aplicables a Max Weber.

${ }^{3}$ Cf. mi estudio introductorio a Max Weber, La Ética protestante y el espíritu del capitalismo, Madrid, Istmo, 1998, pp. 7-91.

4 Cf. Uso aquí esfera en el sentido interno weberiano de esfera de acción social. Para un ensayo de teorizar este punto, puede ver mi trabajo «Esferas de valor y sistema psíquico (Entre Freud y Weber)», en Miscelánea Vienesa, Teresa Rocha Barco (ed.), Cáceres, Universidad de Extremadura, 1998, pp. 219-249.

${ }^{5}$ Cf. Stefan Breuer, Burocracia y Carisma, Sobre la sociología política de Max Weber, Valencia, IVEI, 1996, pp. 171-183.

6 Cf. J. L. Villacañas, «Max Weber y la democracia», Debats, núm. 57-58, otoño-invierno de 1996, pp. 97-116.

7 Las últimas y más apreciables aproximaciones al análisis de la política en Max Weber se puede encontrar en Kari Palonen, Eine Lobrede für Politiker, Ein Kommentar zu Max Webers "Politik als Beruf», Opladen, Leske+Budrich, 2002, y el incluso más importante, Das Webersche Moment, Zur Kontingenz des Politischen, Verlag, Westdeutscher, 1998. Este último es un intento de contestar a Pocock y su libro sobre The Machiavellian Moment.

8 Una edición fragmentaria en la editorial Akal, Madrid, 1982, con el título de Historia agraria Romana, Para este momento productivo de Weber debe verse el trabajo de Realino Marra, Capitalismo e anticapitalismo in Max Weber, Storia di Roma e sociologia del diritto nelle genesi dell'opera weberiana, Bologna, Il Mulino, 2002 
gemeine ${ }^{9}$, su problema más urgente fue estudiar las posibilidades evolutivas de Alemania y su lucha aspiró a hacer de su país una democracia plena. Podemos referirnos a estas cuestiones sociales y constitucionales como la parte objetiva de la política. Su idea central era la de establecer un sistema constitucional apropiado a la sociedad industrial y de masas de Alemania. Sobre este problema proyectó la dimensión subjetiva de la política, que, desde elementos nietzscheanos ${ }^{10}$, atendía al problema de cómo una vocación política verdadera - de corte siempre aristocrático-, podía jugar en una situación social objetiva caracterizada como sociedad de masas, estructuralmente democrática. Por eso, la clave de bóveda de este cruce de elementos objetivos y subjetivos de la política fue la figura del presidente de la repúbli$\mathrm{ca}$, en la que Weber concentró su teoría del carisma anti-autoritario y su tesis acerca de la racionalización material del derecho ${ }^{11}$.

Así que la política no podía reducirse ni a una dimensión puramente objetiva y social, ni a una cuestión puramente subjetiva y personal. No era ni administración de las cosas ni burocracia, pero tampoco pura personalidad irresponsable e irracional ${ }^{12}$. Lo más decisivo del análisis de Weber, que apunta la necesidad de profundos equilibrios, reside en su voluntad de definir la política desde el juego y el cruce de estos dos factores, el de la sociología y el de la subjetividad vocacional del político. Ese doble aspecto es el que vamos a intentar atender en este ensayo. Desde luego, el tema es bien complejo, como todo lo que tenga que ver con Max Weber. En realidad aquí sólo pretendo introducir algunos de sus aspectos.

2. El sentido del liberalismo social en Weber. Es una opinión recibida la de que Max Weber pertenece, por familia y contexto, al universo liberal alemán. Mas, tras las decepciones del nacional-liberalismo bajo la época de Bismarck, este juicio debe ser complementado, si ha de identificar finalmente la posición de Weber. Su relación con Hermann Baumgarten fue decisiva para mantener vivas las reclamaciones radicales del liberalismo del Vormärz. Su vinculación con Friedrich Naumann y los círculos religiosos progresistas protestantes tejió su liberalismo con un amplio contenido social y nacional que le liberó de un conservadurismo incipiente. Su adscripción a

\footnotetext{
9 Conocidos como Parlament und Regierung in neugeordneten Deutschland, editado en Gesammelte Politische Schriften, Tübingen, Mohr, 1958, edición española en Parlamento y gobierno en el nuevo ordenamiento alemán, en Escritos Políticos, México, Folios Ediciones, 1982.

$10 \mathrm{Cf}$. el famoso libro de Robert Eden, Political Leadership and Nihilism. A Study of Weber and Nietzsche, Tampa, University Press of Florida, 1984.

11 La racionalización material del Derecho no ha sido bien estudiada por los analistas de Weber, y, sin embargo, es la función propia del carisma anti-autoritario propio de la democracia de masas. A pesar de todo, puede verse el pequeño comentario sobre el tema en María José Fariñas Dulce, La Sociología del derecho de Max Weber, Madrid, Civitas, 1991, pp. 268-275L.

12 Como en el caso de la percepción de la política romántica por parte del Kaiser. Para la crítica de esta forma de subjetividad y su compulsión irresponsable, puede verse mi trabajo «Dilemas de la responsabilidad. Una aproximación weberiana», en Manuel Cruz y R. R. Aramayo, El repar to de la acción. Ensayos en torno a la responsabilidad, Madrid, Trotta, 1999, pp. 89-112.
} 
la escuela de la economía nacional de Gustav Schmoller le separó, como sabemos, del manchesterismo ${ }^{13}$. Así que, en el caso de Weber, no se trata de un liberalismo doctrinario y clásico, sino de una voluntad de ser liberal, de un liberalismo voluntarista, como ha defendido Hennis, en una época en la que esta opción se siente acorralada entre el conservadurismo de los aparatos del Estado, el desarme ideológico de la vieja generación y la retórica revolucionaria de la socialdemocracia. Weber, en este sentido, es un liberal a pesar de la crisis del liberalismo, que tan certeramente ha estudiado Mommsen en el primer capítulo de su La edad del Imperialismo.

Hennis ha recordado que el liberalismo de Weber no es el liberalismo anglosajón. Ninguna de las premisas que pueden identificar a este liberalismo le es propia. A su actitud heroica le resultaba especialmente despreciable la pacata obsesión de la seguridad del liberalismo burgués. No era Weber un hombre de libertad negativa, de la mera retirada de todos los obstáculos sociales para el libre despliegue del individuo privado. Tampoco creía que, una vez realizada la abolición de los obstáculos, brillara la felicidad universal o la senda del progreso. No pensaba que la libre y pacífica actividad del mercado resolviera los problemas sociales y políticos. Su visión del capitalismo tampoco era desde luego apologética. Más bien lo comprendía como un duro destino con el que teníamos que cargar responsablemente, destino que el socialismo no alteraba, sino que quizás agudizaba. Este mismo hecho despierta la duda acerca de si Weber creía en algún tipo de progreso, de teleología de la historia, de evolucionismo ontológicamente sostenido. En realidad, sólo la ciencia y la técnica eran capaces de mostrar procesos de acumulación objetiva de resultados y, por tanto, de ser pensadas bajo la forma de un progreso, mientras que se mantuvieran estables las necesidades sociales mediadas por las soluciones técnicas. Esta estabilidad, sin embargo, ni era necesaria ni en muchos casos era deseable.

La racionalización, pensada como duro destino por Max Weber, nada tiene que ver con el optimismo ilustrado. De hecho, este progreso técnico no podía sostener ideal alguno, salvo el utilitarista, aquella máxima felicidad para el máximo número. Ahora bien, entre los fines utilitaristas y el ideal humano había para Weber un verdadera heteronomía, según reconoció ante Sombart ${ }^{14}$. Como sabemos, esta heteronomía es paralela a la que existe entre necesidades e intereses, por un lado, y pasión, responsabilidad y sentimiento, por otro. En este sentido, Weber pensaba que cuanto más se impusieran los fines utilitaristas y hedonistas, tanto menos alumbrarían los verdaderos ideales de los hombres. Ésta era una de las tragedias más básicas para

13 Cf. para esta relación y su profunda influencia en la definición de la metodología weberiana, W. Hennis, «Die volle Nuichternheit des Urteils. Max Weber zwischen Carl Menger und Gustav Schmoller. Zum hochschulpolitischen Hintergrund des Wertfreiheitspostulats», en G. Wagner y H. Zipprian (dirs.), Max Weber Wissenschaftslehre, Frankfurt, Suhrkamp, 1994, pp. 105-145.

14 En Carta de 8 de febrero de 1897. 
él y su tensión atraviesa su idea de la política. Como es natural, creía que esta tragedia estaba íntimamente vinculada a la sociedad de masas y el papel en ella de los hombres que sintieran el antiguo aliento de la virtud aristocrática. Como nos recuerda Hennis, se podría hablar de un liberalismo trágico en Max Weber, con lo que se muestra la síntesis compleja de su pensamiento, pues no hay que olvidar que la noción de tragedia le es internamente hostil al universo liberal ${ }^{15}$.

Ahora bien, todo esto en modo alguno ha de sugerir que Weber no viera como inevitables los valores «liberales» de la dignidad humana, la libertad y la igualdad, como valores universales que dependen de algo parecido a un derecho racional. Para él todos los hombres tenían derecho a construir su destino por ellos mismos, y en este sentido, su idea de hombre es muy cercana al individuo autónomo de Kant. Como este autor clásico, también Weber cree que estos derechos naturales no eran nada fuera o más allá del compromiso interno que el hombre, que cada hombre, mantenía en su defensa. En sí mismos eran motivaciones de la voluntad y de la libertad y no venían salvaguardados por código alguno, sino por la lucha mantenida en su defensa. Para Kant, como sabemos, los derechos naturales eran deberes naturales y para realizarlos la persona debía asumir una actitud de rigorismo moral exigente ${ }^{16}$. En este sentido, eran para Weber, como lo había mostrado su amigo Jellinek, «ejemplos de un fanatismo intelectual extremo», propio de aristocracias intelectuales asentadas en una noción de dignidad que conecta con la virtud de las tradiciones republicanas. La concesión de estos derechos de forma pasiva a todos, ese paternalismo humanitarista de nuestra sociedad de masas, era a sus ojos tan inevitable como perturbador. El sociólogo debía reconocerlo, desde luego, El lector de Nietzsche que Weber era, sin embargo, siempre se mantiene fuera de su zona de visión. Al contrario, la tragedia que connota su liberalismo consiste en que la concesión masiva de derechos en las sociedades contemporáneas desactivaba el rigorismo moral que históricamente había luchado por ella.

También es verdad que Weber compartía con el liberalismo su defensa del Estado de Derecho y que su modelo en el fondo era el Estado constitu-

15 W. Hennis, Max Weber Fragestellung, Tübingen, Mohr, 1987, p. 408. Esta dimensión trágica ha sido analizada por Yolanda Ruano de la Fuente, Racionalidad Crítica y conciencia trágica. La modernidad según Max Weber, Madrid, Trotta, 1996.

${ }^{16}$ Cf. para estas bases morales del Derecho moderno, mi Res Publica. Los fundamentos normativos de la política, Madrid, Akal, 1999.

No obstante, el conflicto en Weber no tiene por qué tener la forma del conflicto específico y existencialmente radical que se da entre el amigo y el enemigo en el sentido de Schmitt. Puede haber conflicto político sin que la calificación entre las partes pueda describirse bajo la forma amigo-enemigo, esto es, sin que implique amenaza existencial tal y como Hegel puso de moda con su análisis de las relaciones amo-esclavo. Weber en este sentido es más kantiano y parte de la idea de una insociable sociabilidad que puede desactivar la violencia o bien puede promoverla, según los modos de relación social que promueva. 
cional. La defensa de la libertad personal, las garantías jurídicas para el individuo, la racionalidad de la división de poderes, le parecía indispensable para la promoción de la responsabilidad política. Pero no menos cierto es que Weber también sabía, como el republicanismo kantiano, que esta estructura política sólo podía sobrevivir si los ciudadanos aspiraban a ejercer una verdadera actividad política. Sin que la pasión política prendiera de alguna manera en los pechos de los ciudadanos, las conquistas del llamado Estado liberal resultaban radicalmente frágiles, y perfectamente compatibles, como sabía Tocqueville, con el despotismo. Ahora bien, Weber pensaba que la pasión política era más o menos inevitable sólo en tipos humanos combativos y fuertes. Aquí su republicanismo aristocrático chocaba con el problema de la democracia de masas. Para él, no hay acción política sin una subjetividad capaz de enfrentarse al conflicto de forma decidida. Estas dimensiones, aprendidas en el hombre fuerte de Nietzsche, eran naturalmente ajenas al liberalismo y explicaba su claudicación vergonzosa ante Bismarck. Antes que neutralizar los conflictos, como era propio de liberalismo, Weber pensaba que una actitud responsable pasaba por definirlos y asumirlos, luchando por ellos con responsabilidad.

Jamás se refleja en los textos weberianos la idea de que los hombres pueden convivir sin que se definan formas de dominación, de relaciones de mando y obediencia entre ellos. En este sentido, para Weber, el problema de la política no era la administración de intereses, o de las cosas, sino esencialmente el problema del dominio sobre los hombres, lo que era imposible sin reconocer la autoridad y el liderazgo. Nada puede reemplazar a la dominación personal visible, reconocida, clara. Este punto, junto con la inevitabilidad del conflicto, es el que Schmitt hereda de Weber. A pesar de todo, Weber, por un imperativo aristocrático, compartía con el liberalismo militante contra la sociedad señorial la idea de reducir hasta donde fuera posible la realidad del dominio del hombre sobre el hombre. Esta exigencia era la que ahora debía acreditarse en la sociedad de las masas, que abría posibilidades ingentes de autoritarismo y despotismo. Pero frente al liberalismo doctrinario, que confía en el continuo consenso producido y reproducido por el diálogo, Weber pensaba que la esfera de la política era justo ese ámbito de dominio y de poder personal. Si Weber defendía el individualismo, esta defensa tenía que ver con el hecho elemental de que, sin individuos claros y representativos de ideales, el liderazgo social y político era inviable, y las formas de la autoridad política inalcanzables. El liberalismo, en este sentido, con sus continuas cesiones y acuerdos, apenas era consciente de la especificidad de la esfera de la política. Aunque Max Weber aspiraba con el liberalismo a defender hasta donde fuera posible la libertad, entendía que el espíritu de consenso y de neutralizar los conflictos del liberalismo era una mala estrategia, pues no hacía frente a los verdaderos obstáculos que a la libertad oponía la sociedad de masas. 
3. Democratización pasiva y activa. Se puede afirmar que Weber deseaba fundar una ciencia política responsable sobre un pensamiento sociológico riguroso. Este proyecto, en cierta medida, venía a completar el programa científico de G. Jellinek. Éste había elaborado una monumental Teoría general del Estado que causó profunda impresión en Weber ${ }^{17}$. A decir de Weber, y de muchos más, esta teoría necesitaba de un complemento sociológico, cosa en la que naturalmente no estaría de acuerdo Kelsen. Ahora bien, el dato fundamental de toda sociología que quisiera ser relevante para la comprensión del Estado era la rotundidad del proceso de democratización social. Tomar en serio este proceso reclamaba dinamizar la forma constitucional tradicional. En cierto modo, Weber se sintió animado a este proyecto tras leer, en 1906, el texto de Jellinek Verfassungsänderung und Verfassungswandel. En una carta reconoció que este libro es un paso serio «para el inicio de un estudio científico de la política» ${ }^{18}$. Esta expresión apenas podía significar otra cosa que una ciencia política basada en un conocimiento sociológico fundado 19 .

En Economía y Sociedad Weber analiza este proceso de la democratización como proceso político, social y cultural. En realidad no era el primero que lo hacía. Simmel se había ocupado de él y también constituye la premisa ensayística del Kritik der Zeit de Walter Rathenau. Para todos, sin embargo, la democratización era sobre todo un proceso sostenido por el crecimiento demográfico. Ahora, y éste es el cambio esencial que ellos percibían, todas las relaciones sociales eran relaciones de masa. En política dominaba el gobierno de la masa, en la sociedad se imponían las necesidades de la masa y en la cultura se tornaba dominante el gusto de la masa.

Ahora bien, de los estudios de Weber se deriva una distinción entre democratización activa y pasiva. La primera es de naturaleza política e implica minimizar la dominación del hombre sobre el hombre, como recogía el ideal liberal-republicano. La segunda sólo conlleva una nivelación social de los gobernados, junto con la igual calificación para la gestión de los asuntos públicos, la famosa igualdad de condición u homogeneidad sobre la que, desde Tocqueville, reposaba el creciente despotismo de la opinión pública y de los aparatos del Estado. Esta última democratización implicaba movilidad social y capitalismo innovador de parvenus, pero no implica movilidad política ni nueva selección de dirigentes. Ambas formas de democratización son la sustancia misma de la modernidad; la primera, a nivel político, era canalizada por la teoría del contrato y del consenso, así como una ajustada teoría de la representación y de la división de poderes que eliminara la posi-

\footnotetext{
17 Marianne Weber, Max Weber. Una Biografia, Valencia, IVEI, 1995, p. 484.

18 Carta al autor del 27 de agosto de 1907.

19 Para todo esto, Gangolf Hübinger, «Democratizazione nello stato, nella società e nella cultura: Max Weber tra politica e scienza politica», en Marta Losito y Pierangelo Schiera, Max Weber e le scienze sociali del suo tempo, Bologna, Società editrice Il Mulino, 1988, pp. 455-481.
} 
bilidad del carisma autoritario; la segunda, a nivel profesional, procede de la idea igualmente calvinista de la ética profesional. Por lo demás, ambas ideas estaban muy estrechamente relacionadas, pues sólo una diferencia entre gobernantes y gobernados que repose sobre una democratización pasiva, esto es, sobre una precomprensión de la igualdad profesional básica a todos, puede generar el mínimo gobierno del hombre sobre el hombre que pretende la otra forma de vida democrática libre. Así que, en último extremo, la teoría republicana de la política sólo era verdaderamente viable sobre una sociedad civil profesional. Era posible sobre ella, pero en modo alguno necesaria.

En efecto, aunque unidas por un lejano cosmos cultural, la democratización pasiva y la activa no siempre van parejas en una sociedad. En efecto, la democratización pasiva social no implica en modo alguno la democratización activa. Aquí se deja sentir un eco de la diferencia kantiana entre ciudadano activo y pasivo, ahora ya claramente denunciada como una patología propia de los alemanes y de la sociedad de masas. Si Weber es tan fascinante para una mirada hispana, como la mía, es porque esa patología no nos es en absoluto ajena. En un pasaje de sus informes sociológicos ${ }^{20}$ dice Weber: «Una persona que está acostumbrada diariamente a manifestar poderosos sentimientos únicamente de boquilla, sin relación alguna con su acción, - sin una adecuada canalización de estos sentimientos poderosos expresados en una acción poderosa-, es una persona que, en pocas palabras, fácilmente llega a ser un buen ciudadano en el sentido pasivo de la palabra. No es de extrañar que los monarcas prefieran este tipo de realidades. "Puedes sentarte tranquilamente sobre ellos mientras cantan". Pasiones fuertes y poderosas y grandes acciones faltan aquí». De esta forma, Weber dejaba claro que la ciudadanía pasiva, sostenida por procesos de democratización pasivos, constituía el soporte claro del dominio despótico del monarca. Es muy fácil, pero muy oportuno, recordar el final de Was ist Aufklärung, de Kant, y el sueño del súbdito ideal para el monarca despótico: razonad tanto como queráis, pero obedecer. En cierto modo, la escisión entre sentimientos y acciones representaba la ruptura de aquella personalidad ética unitaria que se había configurado en los decididos hombres de la modernidad reformada.

Un pueblo civil ${ }^{21}$, un concepto que nos recuerda a Maquiavelo, debía reunir las dos formas de la democratización. La forma en que se podía dar la síntesis de ambos procesos de democratización era mediante una genuina representación política. Mediante ella, los ciudadanos pasivos eran capaces de ejercer una actividad política adecuada a sus condiciones sociales de vida. Por la democratización activa, ese pueblo exigiría una forma de elección institucionalizada de sus jefes, se reservaría siempre la capacidad de retirarle su confianza y mantendría la posibilidad de influir sobre valoracio-

${ }_{20}$ «Geschäftsbericht und Diskussionsreden auf den deutschen soziologischen Tagungen», en Gesammelte Aufsätze zur Soziologische und Sozialpolitik, Tübingen, Mohr, Siebeck, 1988, p. 445.

${ }^{21}$ Baumgarten, Max Weber, Lebens und Werke, Tübingen, Mohr, 1988, p. 429. 
nes y decisiones políticas con el ejercicio de la opinión pública. Por la democratización pasiva, el pueblo alcanzaría un valor de su propia dignidad mediante un trabajo libre en consonancia con la conciencia jurídica moderna, que no reconoce ninguna sumisión personal al patrón empresarial, sino a la empresa. Por la democratización activa, basada en el individualismo democrático, un pueblo «demuestra la decidida voluntad de una nación de no dejarse gobernar como un rebaño de ovejas» ${ }^{22}$. La clave entonces de la síntesis, y de una representación política adecuada, era que los líderes lo fueran de verdad, que fueran ciudadanos activos en el sentido más fuerte de la personalidad vocacional política.

Una democratización pasiva no implica ese descubrimiento de las virtudes republicanas que permite alcanzar una democratización activa. Pero una falta de democratización pasiva hace inviable por sí misma la democratización activa de largo alcance y de una apropiada capacidad racionalizadora. Un orden social de castas, de privilegios y de estamentos cerrados, de coacciones sociales cercanas a la servidumbre, donde el igual acceso a los puestos de trabajo y a los cargos es inviable, y donde el mérito profesional no cuenta, genera claramente un dominio mayor del hombre sobre el hombre e impide el florecimiento de la dimensión política tendente a reducir al máximo el dominio del hombre por el hombre. El mecanismo preferido de poder para el hombre es, desde luego, el poder difuso social, porque implica una dominación irresponsable y un dominio de las cosas que atenaza al hombre con más fuerza que el vínculo político de mando y obediencia claro. El dominio político supone por eso una sociedad menos capaz de imponer dominación difusa y social. Donde no hay libertad social, una societas civilis libre, no puede haber res publica. Así que el reto efectivo de la modernización social es doble: impulsar los elementos culturales, económicos y profesionales de la democratización pasiva y, además, estar en condiciones de fundar sobre ella una genuina, aunque mínima, relación de mando y obediencia política basada en la democracia activa. Ésa era la síntesis de los ideales de igualdad y libertad, con sus consecuencias sobre el hombre democrático y aristocrático que en cierto modo Weber soñaba.

En realidad, en la opinión de Weber, Alemania estaba desigualmente atrasada en relación con estas dos formas de democratización. Respecto de la pasiva opinaba que, por mucho que se hubiese desarrollado una articulación profesional moderna en los ámbitos de la producción económica, seguía muy vigente el orden estamental prusiano, de origen feudal, en el que las personas se atrincheraban en su rango familiar, con sus prebendas seculares. El prestigio de esta casta era tal que seducía a la burguesía, deseosa de gozar de la estabilidad social y del prestigio de la nobleza, y del disfrute de bienes apartados del tráfico social variable. Tal cosa la ha estudiado Norbert

${ }^{22}$ Max Weber, Gesammelte Politische Schriften, Tübingen, Mohr, 1988, pp. 63 ss. 
Elias en una magnífica obra ${ }^{23}$. Ahora bien, aquellas prebendas implicaban casi automáticamente una posición de poder en el seno del Estado y de acceso a los cargos políticos, y una utilización del prestigio social para ejercer una dirección política nunca cuestionada. De esta forma, el déficit en democratización pasiva interesaba muy negativamente a la democratización activa. Era fácil que estas castas se representaran su mando político como natural y reclamaran una obediencia como algo igualmente inevitable. En el fondo, ese mando estaba legitimado por funciones de protección, que las clases burguesas, en cierta medida, aceptaban gustosas, pues de esa manera no tenían que encarar las responsabilidades de enfrentarse al conflicto. Así que aquellas diferencias sociales implicaban una comprensión del dominio político. Una falta de democratización social implicaba una falta de democratización política y una posibilidad de limitar el sentido de la dominación.

Por eso es fácil suponer que el diagnóstico de Weber fuese pesimista. Los rudos fenómenos de la democratización, en tanto desnudo proceso social de aumento de población, de aumento de intervención de las masas en la producción, de visibilidad de las masas en las ciudades, de protagonismo de las masas en la vida social, se mantenían en Alemania como un rumor sordo, como la crecida de un torrente impetuoso, que no encontraba cauce adecuado ni en la sociedad ni en la política. Para Weber, este fenómeno disminuía considerablemente las oportunidades de Alemania para convertirse en un pueblo civil, coherente y moderno.

Pueblo civil, pueblo coherente, Kulturvolk es lo más distinto de una pueblo escindido entre prebendados y plebeyos. Dividido en estas estructuras arcaicas, la nación alemana no podía entrar con garantías en un proceso de intervención de relevancia mundial. Pero separarse de estas estructuras implicaba otra forma de seleccionar elites, sobre la base de una genuina democratización pasiva que eliminara las posiciones de privilegio social de la nobleza. El mayor reto de construir una sociedad coherente se presentaba de bruces ante Alemania. Pues no hay desafío más importante que pasar de una forma tradicional de selección de elites sociales a una forma nueva y sentida como legítima. Este problema, que había costado mucha sangre en la Europa moderna en su larga lucha por la representación política, era el más urgente. Pues implicaba una cierta fase de anomia. Sobre el espacio vacío de

\footnotetext{
${ }^{23}$ Norbert Elias, Studien über die Deutschen. Machtkämpfe und Habitusentwicklung im 19 und 20. Jahrhundert, Frankfurt, Suhrkamp, 1989. Versión italiana, Il tedeschi, Lotte di potere ed evoluzione dei costumi nei secoli XIX e XX, Bologna, II Mulino, 1998. La tesis de base es la siguiente: «La nobleza alemana legitimaba ampliamente la pretensión de superioridad en virtud de un árbol genealógico ininterrumpido y posiblemente privado de intromisiones burguesas. Por el contrario, la secreta pretensión de los patricios holandeses - y lo mismo vale para la nobleza inglesa- encontraba su propia legitimación en un comportamiento particular», p. 20. Lo peculiar fue que en Holanda e Inglaterra fue posible una imitación por parte de las clases burguesas, mientras que en Alemania lo que se imitó fue la vinculación a linajes nobles. «Entró así en escena una particular variedad de la burguesía: aquellos burgueses que hicieron propio el tenor de vida y las normas de la noble militar», p. 22.
} 
una democratización pasiva de alcance general, se debían ahora establecer las discriminaciones pertinentes para decidir quién debía mandar, durante cuánto tiempo y hasta qué punto. En este problema Alemania naufragó. Pero en este mismo problema naufragó cualquier sociedad que compartiera con más o menos fuerza estas premisas. La española era una de ellas.

La Alemania de Weber, por tanto, conoció las dificultades propias de una época de tránsito. Es verdad que el reto era tanto más difícil cuanto más rápido se hubiese dado el proceso de crecimiento de población, la transformación de las formas de trabajo, el cambio de horizonte social, el paso de la sociedad agraria a la sociedad urbana, el desarraigo de la cultura tradicional. En medio de este vertiginoso cambio, se debía construir una sociedad nacional, esto es, un pueblo capaz de disponer de la madurez de elegir una forma de dominación política mínima, capaz de garantizar su libertad, pero efectiva, capaz de resolver los retos de una sociedad industrial y de una política democrática de masas con incidencia mundial. Este pueblo tenía que estar unido por una concepción del mundo cívico-fraternal que, como Hennis ha señalado, debía ser de naturaleza republicana clásica ${ }^{24}$. Sobre esta comprensión de la vida cívica de un pueblo tenían sentido las formas representativas y plebiscitarias de la democracia. Como es fácil comprender, la democracia formal era más bien poca cosa sin esta democracia interna, poseedora de elementos sustantivos y claramente formadores. Como Weimar pronto se encargaría de demostrar, si no existen estos elementos que podemos llamar de convicción política, la forma política institucionalmente democrática resultaba imposible.

4. Dificultades estructurales: Burocratización. El obstáculo no sólo se levantaba por el carácter vertiginoso de la democratización social como hecho desnudo de masificación. Ante el proyecto de hacer de Alemania un pueblo civil, también se alzaba la muralla de la burocratización. En cierto modo, esto es conocido. Por eso hablaré de este asunto sólo desde cierto punto de vista. Claramente, la burocratización tiene su razón de ser en la masificación. En cierto modo, la hace efectiva y la fomenta. En resumen, hay entre estos fenómenos una relación de dependencia recíproca ${ }^{25}$. Al igualar jurídicamente a los individuos en la aplicación de los reglamentos, al demoler los privilegios en el trato administrativo, al basarse en el mérito como forma de acceso al cargo, la burocratización fomenta la democratización pasiva. Sin embargo, y a pesar de su carácter más bien impersonal, no podemos decir que la burocracia sea un mínimo poder del hombre sobre el hombre. Se trata antes bien de un proceso de una democratización pasiva, que no promueve la correspondiente democratización activa. Al contrario, forma cadenas rígidas de mando, duraderas, sólidas, que acostumbra al

${ }^{24}$ W. Hennis, Max Weber Fragestellung, Tübingen, Mohr, 1987, p. 295.

${ }_{25}$ Max Weber, Wirtschaft und Gesellschaft, Fünfte Revidierte Auflage, Tübingen, Mohr, 1976, kapitel IX, Herrschaftssoziologie, 2 Abschnitt, Bürokratische Herrschaft, pp. 567-571. 
hombre a la irresponsabilidad, a la falta de visibilidad, al ocultamiento en medio de las cadenas de mando y a la aceptación pasiva del último jefe. Si no tiene en su cima un mando político serio, nombrado por el ciudadano que la obedece, la burocracia rompe todas las virtudes políticas de la democratización, las únicas que pueden minimizar el dominio del hombre sobre el hombre. En este sentido, la burocracia es la potencia más hostil al espíritu republicano.

Este desequilibrio entre burocracia y poder político democrático constituía uno de los rasgos básicos de Alemania. En la cima de la burocracia no se sentaba el Estado democrático, sino las figuras propias de un Estado autoritario y tradicional. Con ello, la burocracia no estaba sometida a la presión de la responsabilidad. En ausencia de esta presión, los funcionarios desarrollaron su propia ética, que ha sido definida por Weber de manera magistral. Ahora no podemos entrar en ello. Lo decisivo es que, en la opinión de Weber, con esta burocracia se comprometía «el rango de potencia internacional y de desarrollo civil de un país.» ${ }^{26}$. Como vemos, Weber siempre identifica la coherencia civil de una nación con su optimización para jugar con fuerza en la política mundial. En todo caso, aquí dice que la burocratización irresponsable impide ambos procesos. La democratización activa implicaba ciertamente un principio de control político de la burocracia. Con ello, Weber se oponía a las tesis de Otto Hintze y Gustav Schmoller acerca del carácter ilustrado de una burocracia autónoma, directamente al servicio del soberano. En cierto modo, la burocracia configuraba su carácter definitivo no desde sí misma, sino desde el último mando.

Como dice Weber en los ensayos de Religionssoziologie ${ }^{27}$ democratización y burocratización racional debida al mérito suponen y potencian una ordenación social de clase [Klassenlage], no una ordenación en estamentos [Ständische Lage]. El atraso alemán en este terreno también era muy claro. Como luego ha reconocido la investigación más rigurosa ${ }^{28}$, lo propio de Alemania era la superposición de esos dos principios organizativos de la sociedad. Mas no sólo eso. También fue propio de Alemania que, en la pugna inevitable que estos dos cosmoi sociales impulsaron, llevase las de ganar el principio estamental.

En efecto, cada uno de estos principios genera una dinámica de reconocimiento que le es propio. La organización estamental aspira al honor exclusivo, al aislamiento, a su conversión en casta, con el consiguiente deseo de monopolizar la posibilidad de rentas y ganancias y utilizar a su favor el apa-

\footnotetext{
${ }^{26}$ Max Weber, Gesammelte Aufsätze zur Soziologie und Sozialpolitik, «Diskussionsreden auf den Tagungen des Vereins für Sozialpolitik», Tüibingen, Mohr, Siebek, 1988, p. 413.

27 Gesammelte Aufsätze zur Religionssoziologie I. Mohr, Tübingen, Einleitung, p. 274; versión española en Ensayos de Sociología de la Religión, Madrid, Taurus, 1983, «La ética económica de las religiones universales. Introducción», p. 221.

28 R. Koselleck, 1988. Prussien zwischen Reform und Revolution, Stuttgart, Klett-Cotta, 1986.
} 
rato del Estado para mantener monopolios y privilegios. Autorreferenciales en su pretensión de hegemonía, sus principios de vida económica y social no necesitan el reconocimiento de todos, y en este sentido son altamente irracionales.

6. Tras Nietzsche: autogobierno y señorío. Weber subrayaba en este punto las diferencias con Inglaterra. Aquí, la aristocracia no se convirtió en casta, sino que se democratizó con el self-government burgués, hasta inspirar la forma de vida de una nación segura de sí misma ${ }^{29}$. En lugar de este movimiento expansivo, que deja sentir una forma de vida valerosa sobre amplias capas de la población que lidera, en Alemania, la aristocracia se ha protegido y defendido, lanzando sobre toda la población un deseo de participar en las formas de vida propias de la feudalización con soporte del aparato del Estado. Las posibilidades de éxito en medio de esta armazón feudal estaban reservadas a los parvenus, que aunque muy activos desde el punto de vista económico, eran incapaces de gozar de un reconocimiento político de su éxito. El capitalismo puro, en esas condiciones, no podía generar una democratización activa.

Con plena lucidez, Weber comprendió que el mayor obstáculo para una real democratización activa y pasiva residía en la dificultad de superar aspectos irracionales de la vida social, como criterios de prestigio, de gusto, de actitud. Para él, las diferencias sociales más insoportables de todas, las que producían un complejo de inferioridad insuperable, $y$ un resentimiento y auto-desprecio paralizante, eran las «de cultura y gusto». No cabía duda de que el tono en cuestiones de prestigio y gusto lo daba la cultura feudal de la aristocracia prusiana. Por eso, en el ámbito de una política de democratización radical eran tan importantes las cuestiones de cultura, de educación en el sentido alemán de Bildung, esto es, de aquella capacidad autónoma para configurar todos los aspectos de la propia vida, y entre ellos los estéticos. De esta autonomía dependía el sentimiento de la propia dignidad y, con ella, la capacidad de mantener a distancia las seducciones propagadas por la brutalidad de las formas de vida de los Junkers.

No es de extrañar que todo este programa mantenga en Weber los aires de la vieja heroicidad burguesa, en lucha contra una realidad feudal dominante. En este sentido, y como ya hemos visto, la guía más básica de su combate era la lucha contra los privilegios históricamente injustificables de los Junkers. Ante esos residuos históricos, muy activos y poderosos, Weber reclamaba la «radical democratización social» ${ }^{30}$. Era en el fondo la última oportunidad de la democratización activa y política.

Pero una ordenación social de clases planteaba, como ya vimos, nuevos retos a la construcción de una sociedad nacional. Ante todo, Weber reclama-

${ }^{29}$ Max Weber, Gesamtausgabe; Abteilung I, Band 15, Zur Politik im Weltkrieg, Schriften und Reden, Tübingen, Mohr/Siebeck, 1984, pp. 386-388.

${ }^{30}$ Gesammelte Politische Schriften, «Deutschlands künftige Staatform», op. cit., p. 449. 
ba que una sociedad de clases sólo configura un pueblo unitario si todas las clases se implican en el Estado como socios. Tras los primeros años del nuevo siglo, en los que se culmina la crítica al organicismo nacionalista, no hay en Weber una visión nacional romántica. No se trata de tejer sentimientos de solidaridad, ni de fusiones de anhelos, ni de entusiasmos poéticos. Que las clases se vean como socios de un Estado implica que se reconozcan como legítimos los intereses contrapuestos y que el Estado se gestiones desde un acuerdo racional sobre los mismos.

En su artículo «Derecho electoral y democracia en Alemania» ${ }^{31}$, Weber extrajo las últimas consecuencias de estas posiciones, al reclamar de una forma nítida una democratización activa sobre una general democratización pasiva. No se podía sostener un Estado que, por una parte, reconocía su dependencia del trabajo libre de sus masas y, por otra, no reconocía sus derechos políticos y constitucionales. Tal Estado convertía a las masas de los trabajadores profesionales libres en un mero objeto pasivo y ajeno a las decisiones del gobierno. Como resultaba inevitable que tales masas dispusieran de una fuerza considerable, reducirlas a la situación de meros objetos pasivos los condenaba a dirigir toda su fuerza contra ese mismo Estado. En este artículo, Weber reclama la necesidad de democratización política de Alemania, si ésta ha de convertirse en un pueblo de señores. Vemos así que pueblo civil y pueblo de señores políticos significa la misma cosa para Weber. No se trata de un enunciado imperialista, ni juega esencialmente dentro de una previsión concreta de relaciones internacionales. Es un enunciado auto-referencial. No se trata de que otros reconozcan a los alemanes como señores, sino de que éstos se vean a sí mismos como tales, esto es, gobernados por sí mismos. Básicamente, un pueblo de señores es el que realmente mantiene un régimen democrático. Otra cosa es que sólo un tal pueblo hará, y se le consentirá hacer, una política de dimensiones mundiales. Si todos los hombres de ciencia y de Estado alemanes hubieran condicionado, con la fuerza que lo hizo Weber, una política de influencia mundial a una forma rigurosamente democrática, la fortuna de Alemania en el siglo XX hubiera sido muy otra. Para hacer esta conclusión un poco más evidente, bastaría recordar el cosmos contrario, el que realmente triunfó, aquél se basaba sobre la forma específicamente patológica de capitalismo imperialista de von Bülow, y el nacionalismo sentimental del último Káiser. Este cosmos, que destruyó Alemania, habría sido inviable desde una política responsable capaz de atender los intereses de un capitalismo racional orientado al mercado y de los intereses de las masas trabajadoras conscientes de sus deberes y derechos políticos. Ésa era, sin duda, la base sobre la que edificar una legitimidad democrática, racional legal tanto desde el punto de vista formal como material del Derecho, basada en una representación propia del carisma anti-autoritario, el único compatible con la dominación racional.

${ }_{31}$ MWG, $1 / 15$, op. cit., p. 396. 
Pero la forma de este carisma, la actualización plena del espíritu republicano en la sociedad de masas, es otro tema. En todo caso, el que nos hemos propuesto abordar aquí, la correcta relación entre la democracia pasiva y la activa me parece una variación más de la vieja sentencia que pretende coordinar la societas civilis con la res publica. Por último, una confesión retórica: he empleado siempre el tiempo pasado al hablar de las opiniones y creencias de Weber. En realidad, no lo he hecho porque creyese que todas ellas corresponden a un pretérito que no nos afecta. Sencillamente, se trata de un procedimiento retórico que nos obliga, con tanta más fuerza, a preguntarnos por lo que de esas opiniones y diagnósticos todavía hoy es efectivo y operativo en nuestras sociedades ibéricas. 